\title{
Latex enzyme immunoassay for measuring IgG antibodies to rubella virus
}

\author{
G Duverlie, C Roussel, M Driencourt, J Orfila
}

\begin{abstract}
A latex enzyme immunoassay (LEIA) for detecting IgG class antibody to rubella virus was compared with the latex agglutination test (LA) and a haemagglutination inhibition assay (HI). Of 243 sera tested, four discrepant results were observed among all three techniques, corresponding to borderline values. Except for one sample containing specific IgM class antibody, the difference between quantitative results from each pair of tests was always within a value corresponding to two doubling dilutions and was considered to have acceptable variation. The LEIA technique allowed 10 seroconversions to be detected, as determined by the other techniques. The LEIA required a single 1 in 8 sample dilution, took 30 minutes, and provided a useful alternative assay for the quantitation of rubella antibodies.
\end{abstract}

Serodiagnostic tests for rubella are universally used to confirm rubella infection and to determine immune state. The haemagglutination inhibition assay (HI) is still used for the quantitation of rubella antibodies in France even though false positive reactions may result from residual non-specific inhibitors. Because of rubella immunisation programmes and the need to determine the immunity of women before they become pregnant, new and rapid qualitative assays have been developed. In particular, the latex agglutination test (LA) requires no pretreatment of serum or elaborate equipment and can be performed in a matter of minutes. Qualitative results of the rubella latex tests were reported to correlate well with those of the HI..$^{1-5}$ But for titrating antibody, these LA card tests are not very appropriate because of the need to repeat the test with increased dilutions and the subjective titre reading. We therefore recently developed an assay using the same antigen sensitised latex either in an LA test or in a microparticle enzyme immunoassay for quantitation of IgG antibodies to human cytomegalovirus. ${ }^{6}$ In this study we assessed whether the same Rubella virus antigen sensitised particles could be used for latex agglutination or for latex enzyme immunoassay (LEIA). The technique differed from that used for cytomegalovirus antibodies in that it required different material and procedure and a shorter turn around time. The level of detection was arbitrarily set at $10 \mathrm{IU} / \mathrm{ml}$, as the clinical importance of titres below 10-15 $\mathrm{IU} / \mathrm{ml}$ has not been well established. ${ }^{47}$

\section{Methods}

Twenty two samples, each with HI, LA, and enzyme linked immunosorbent assay (ELISA) results known to be negative, were tested to evaluate the cut-off value of the LEIA Twenty positive control sera were selected to assess the dilution effect on LEIA titres at a 1 in 8 dilution recommended for the test rather than the 1 in 64 dilution required for quantitation of high titre sera. The intra-assay and inter-assay coefficients of variation for LEIA titres were evaluated by testing a low titre serum and a high titre serum 30 times, and these pairs of measurement were used to estimate the intra-assay and interassay repeatability of results. Thus 30 sera for the LA, 34 for the LEIA, and 100 for the HI assay were selected because titres extended across the whole range of typical values, and they were titrated again. Otherwise 243 sera were assayed for comparison of the LA and the LEIA with the HI test. Twenty negative specimens and 20 samples with low antibody titres (8-16), as determined by the HI assay, were included in the trial. A further 203 serial samples submitted for the determination of rubella immunity were examined by LA, HI, and LEIA. Finally, 21 sera from 10 patients who had seroconverted were tested. Two of them were immunised with live attenuated rubella vaccine; the other eight patients had rubella infection. Rubella IgM antibodies were detected in each case by anti- $\mu$ immunocapture enzyme immunoassay (Diagnostics Pasteur, Marnes la Coquette, France).

\section{HI TEST}

The RubeHIT test is a standard haemagglutination inhibition assay (Behring, Marburg, Federal Republic of Germany). The sera were treated with kaolin to remove nonspecific inhibitors, and stabilised human $\mathrm{O}$ erythrocytes were used as indicator cells. Positive and negative control sera were supplied by the manufacturer. A titre of 8 , corresponding to the initial 1 in 8 dilution, was regarded as the lowest positive result.

LA TEST

The Rubalex test is an indirect latex agglutination test produced by Orion Diagnostica, Espoo, Finland. Undiluted serum $(25 \mu \mathrm{l})$ was pipetted on to a test card. The same volume of 
a suspension containing latex particles coated with rubella virus antigen was added and mixed carefully with the serum, and the card was tilted for three minutes. The test was regarded as positive if agglutination was seen within this time. To compare this latex agglutination procedure with other methodologies, doubling dilutions of positive sera in $0.9 \%$ sodium chloride were prepared and tested in the same way. The end point titre was taken as the reciprocal of the highest dilution showing sharp agglutination. Four different latex antigen batches were used during the course of the study with the same determined lower detection limit of $10 \mathrm{IU} / \mathrm{ml}$.

\section{ENZYME IMMUNOASSAY}

The Enzygnost rubella assay is an indirect enzyme linked immunosorbent assay for detecting IgG class antibody to rubella virus (Behring). A dilution of 1 in 40 of the serum was tested to assess the negative results obtained by the HI test and LA tests. Twenty two sera were screened and used to determine the cut-off value of LEIA.

\section{LATEX ENZYME IMMUNOASSAY}

The LEIA was performed with rubella virus antigen sensitised latex particles (Rubalex) as a solid phase immunoadsorbent. The principle was similar to that of a heterogeneous noncompetitive indirect immunoassay such as the ELISA mentioned above. The latex was separated from the liquid phase by filtration using a 96-well membrane-bottomed plate. A silent monitor plate with $0.45 \mu$ m Loprodyne nylon membrane (low protein binding nylon) and an appropriate vacuum filter holder were purchased from Pall Biosupport Corporation, New York, USA. An in-house 96-well dispenser using $1.25 \mathrm{ml}$ Combitips (Eppendorf, Hamburg) permitted simultaneous distribution of each reagent between eight and 96 wells. Before use, to saturate the protein adsorption sites of the membrane, $1 \%$ casein in $0.15 \mathrm{M}$ phosphate buffered saline, pH 7.4 (PBSC), was added at a volume of $150 \mu \mathrm{l}$. After one hour at room temperature the contents of the plate were sucked out and the wells washed with $200 \mu \mathrm{l}$ of PBS. The plates were air dried and were stored at $4^{\circ} \mathrm{C}$ before use. For the test itself, all steps were performed at room temperature (19$21^{\circ} \mathrm{C}$ ). A volume of $20 \mu \mathrm{l}$ of latex suspension was pipetted into each well of the plate and 100 $\mu$ l of one single 1 in 8 dilution of the serum in PBSC was added.

After incubation for five minutes vacuum filtration was started at an operating pressure of $27000 \mathrm{~Pa}(200 \mathrm{~mm} \mathrm{Hg})$. Each reagent was then added after one minute to permit the drainage through the bottom of the plate. The latex particles were washed with $300 \mu$ l PBS. The goat anti-human IgG peroxidase conjugate (Tago, Burlingame, California, code 2390) was diluted 1 in 6000 in PBSC and $300 \mu \mathrm{l}$ were added. The plate was washed twice more and the vacuum aspiration was stopped. A volume of $150 \mu \mathrm{l}$ of the solution of the OPD substrate (Behring) was dispensed and the reaction was stopped after five minutes by adding $100 \mu \mathrm{l}$ of

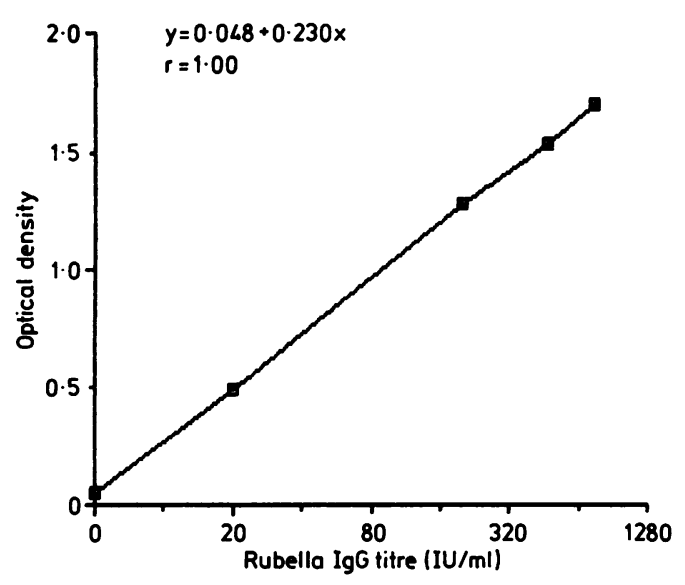

Figure 1 Calibration curve for LEIA.

IN sulphuric acid. The contents of the plate were then transferred by filtration to a flat bottomed plate (Nunc, Roskilde, Denmark). A further volume of $100 \mu \mathrm{l}$ of $0.9 \%$ sodium chloride was added to the membrane to collect all the coloured substrate solution. The optical density was measured in a microplate reader MR 600 (Dynatech Laboratories Inc., Alexandria, Virginia) with the test wavelength at 490 $\mathrm{nm}$ and the reference wavelength at $620 \mathrm{~nm}$

To determine the titre of IgG antibodies to rubella virus in $\mathrm{IU} / \mathrm{ml}$, we used a Rubella Quantitation Panel (Abbott Laboratories, Chicago, Illinois). The five standards $(0,20$, 200,470 and $7.50 \mathrm{IU} / \mathrm{ml}$ ) are referenced according to the Second International World Health Organization Rubella Reference Serum. The absorbance values were then used to prepare a reference curve (fig 1). The calibration data could be fitted linearly by least squares fit. The anti-rubella IgG concentrations of the samples were calculated from the regression equation using their individual absorbance. The cut-off value was arbitrarily set to $10 \mathrm{IU} / \mathrm{ml}$. Specimens with absorbance values greater than that of the $750 \mathrm{IU} / \mathrm{ml}$ standard were retested after an additional 1 in 8 dilution.

Statistical analysis was performed using all titres expressed as logarithm to base 2 . A logarithmic titre of 1,2 , or 3 corresponded to respective titres of 10,20 , and $40 \mathrm{IU} / \mathrm{ml}$ for the LA and LEIA and 8, 16, and 32 for the HI. For analysis of repeatability of each technique and comparison of the three techniques in pairs, a method of analysis recently proposed by Altman and Bland was adopted. ${ }^{89}$ Logarithmic titres obtained by the three assays were tabulated using result differences/mean plot to display relative agreement. For the results from each pair of tests, the mean difference (d) and the standard deviation (s) of the differences were calculated. The mean difference indicates the bias between the two tests and the standard deviation of the difference is indicative of their variability. Most points on the graph are expected to lie between $d \pm 2 s$. These are the limits of agreement. For each technique, the coefficient of repeatability is defined as twice the value of the standard deviation of differences between pairs of measurement. Regression analysis and calculation of the correlation coefficient were also performed. 
Table 1 Intra-assay and interassay repeatability of $H I$, $L A$, and LEIA titres using paired t test

\begin{tabular}{lrl}
\hline & $n=$ & Standard deviation \\
\hline Intra-assay: & & \\
HI & 100 & 0.45 \\
LA & 30 & 0.56 \\
LEIA & 30 & 0.29 \\
Interassay: & & \\
HI & 100 & 0.60 \\
LA & 30 & 0.69 \\
LEIA & 34 & 0.58 \\
LEIA(1/8):LEIA(1/64) & 22 & 0.54 \\
\hline
\end{tabular}

Table 2 Qualitative comparison of test $L A, L E I A$, and HI results

\begin{tabular}{lcc}
\hline & HI positive & HI negative \\
\hline LA + LEIA + & 204 & 0 \\
LA + LEIA - & 0 & 1 \\
LA - LEIA + & 1 & 0 \\
LA - LEIA - & 2 & 35 \\
\hline$+=$ positive; - = negative.
\end{tabular}

Table 3 Comparison of LA test and LEIA in relation to HI test

\begin{tabular}{llc}
\hline & $L A$ & LEIA \\
\hline Sensitivity & $98 \%$ & $99 \%$ \\
Specificity & $97 \%$ & $100 \%$ \\
Predictive values of & $99 \%$ & $100 \%$ \\
$\quad$ positive result & $92 \%$ & $94 \%$ \\
negative result & $92 \%$ & $99 \%$ \\
\hline
\end{tabular}

Table 4 Comparison of rubella titres obtained from $\mathrm{HI}$, $L A$, and $L E I A(n=243)$

\begin{tabular}{lrrr}
\hline$Y: X$ & LEIA:LALA:HI & LEIA:HI \\
\hline Mean difference & 0.16 & -0.09 & 0.08 \\
Standard deviation of the & & & \\
differences & 0.60 & 0.73 & 0.69 \\
Limits of agreement & -1.04 & -1.55 & -1.30 \\
& 1.36 & 1.37 & 1.46 \\
Linear regression slope & 0.97 & 0.96 & 0.97 \\
Intercept & 0.25 & 0.08 & 0.19 \\
Correlation coefficient & 0.97 & 0.95 & 0.96 \\
\hline
\end{tabular}

\section{Results}

The mean absorbance and the standard deviations by LEIA of the 22 LA, ELISA, and HI negative sera were $0 \cdot 107$ and $0 \cdot 023$. This absorbance is about 7 standard deviations lower than that of the threshold value corresponding to 10 $\mathrm{IU} / \mathrm{ml}$. Linear regression analysis was applied to 20 calibration curves. The probability levels corresponding to the $\mathrm{F}$ ratio ranged from 0.001 to 0.0001 for 19 times and the correlation coefficients ranged from 0.992 to 0.999 . Only once were the probability level and the correlation coefficient 0.005 and 0.974 , respectively. The intra-assay and interassay coefficients of variation of the LEIA were respectively, $12.4 \%$ and $14.4 \%$ for low titre sera (mean titre $=13$ $\mathrm{IU} / \mathrm{ml}$ ), and $5.2 \%$ and $10.5 \%$ for high titre sera (mean titre $=280 \mathrm{IU} / \mathrm{ml}$ ).

Analysis of the results of paired testing of sera to assess the repeatability of each technique is presented in table 1. LEIA was significantly more reproducible than $\mathrm{HI}$ and LA $(\mathrm{p}<0.05)$ for intra-assay, but interassay repeatability of the three tests was comparable. Intra-assay repeatability was lower than interassay repeatability for $\mathrm{HI}(\mathrm{p}<0.05)$ and for LEIA ( $p<0.002)$.

A comparison of qualitative results obtained by the three assays is shown in table 2 . Four $(1.6 \%)$ discrepant results were observed which corresponded to borderline values. In table 3 sensitivity and specificity of LEIA and LA test are presented and compared with those of the HI test.

Comparison of the quantitative results from each pair of tests is shown in table 4 . The $95 \%$ confidence interval of the mean of the differences includes the value zero except for the mean of the differences between LEIA and LA, because the LEIA values were slightly higher than those of the LA $(p<0.01)$ The variances of the differences were compared with each other and with the variances of the interrepeatability assays. The variance of the differences between LEIA and LA was significantly lower than those for LA and HI and
Figure 2 Graph showing correlation between $\mathrm{HI}$ and LEIA titres ( $\log _{2}$ ). The numbers represent the frequency value of the sera with the same mean titre and the same difference between their LEIA and
HI titres: $d$ is the mean difference and $s$ the standard deviation.

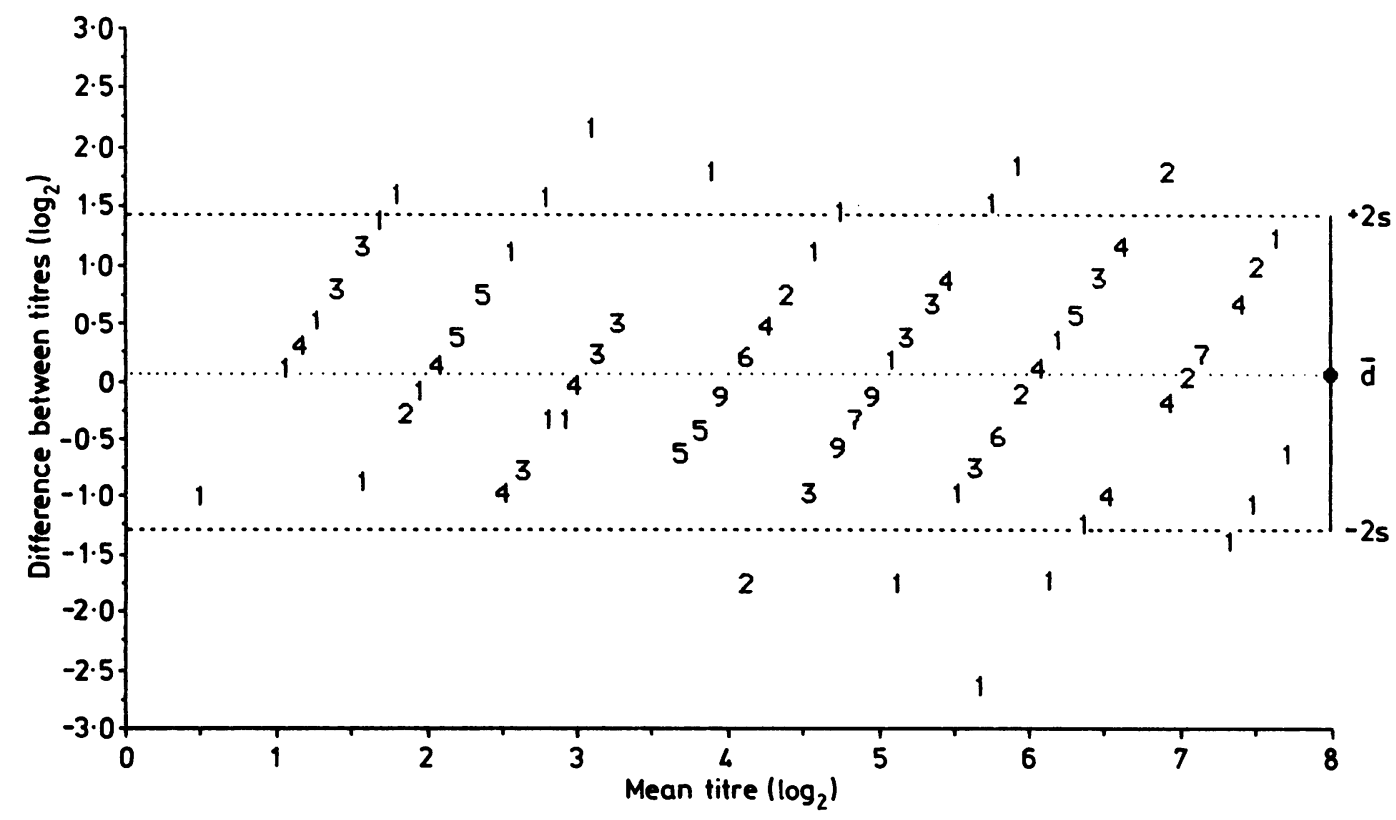


Table 5 Results of three serological tests on sequential sera from 10 patients related to time of onset of symptoms or vaccination

\begin{tabular}{lrrrr}
\hline $\begin{array}{l}\text { Patient's } \\
\text { Serum No }\end{array}$ & Days & $H I$ & $\begin{array}{l}\text { LA } \\
(I U / m l)\end{array}$ & $\begin{array}{l}\text { LEIA } \\
(I U / m l)\end{array}$ \\
\hline 1A & 0 & $<8$ & $<10$ & $<10$ \\
1B & 5 & 8 & 40 & 12 \\
1C & 20 & 1024 & 320 & 330 \\
2A & 5 & 32 & 20 & 13 \\
2B & 19 & 1024 & 320 & 150 \\
3A & 0 & $<8$ & $<10$ & $<10$ \\
3B & 20 & 256 & 160 & 44 \\
4A & 0 & $<8$ & $<10$ & $<10$ \\
4B & 30 & 512 & 320 & 140 \\
5A & 0 & $<8$ & $<10$ & $<10$ \\
5B & 25 & 256 & 160 & 82 \\
6A & 1 & $<8$ & $<10$ & $<10$ \\
6B & 9 & 512 & 640 & 120 \\
7A & 0 & $<8$ & $<10$ & $<10$ \\
7B & 21 & 256 & 320 & 460 \\
8A & 0 & $<8$ & $<10$ & $<10$ \\
8B & 24 & 128 & 160 & 220 \\
9A & 0 & $<8$ & $<10$ & $<10$ \\
9B & 30 & 64 & 40 & 59 \\
10A & 0 & $<8$ & $<10$ & $<10$ \\
10B & 30 & 32 & 40 & 68 \\
\hline
\end{tabular}

In cases 1 to 8 , rubella infection was observed clinically. Cases 9 and 10 were sampled before and after vaccination.

LEIA and HI ( $p<0.03)$. The variance of the differences between LA and HI was significantly higher than those of the differences between $\mathrm{HI}$ and $\mathrm{HI}$ and between LEIA and LEIA $(\mathrm{p}<$ $0.01)$. Linear regression analysis between the titre values of each pair of techniques is also shown in table 4 . The $99 \%$ confidence interval of the three slopes includes the value one and that for the intercepts includes the value zero except for the regression of LEIA titres on LA titres where the intercept corresponds to a significant value. Figure 2 shows the difference between the results of LEIA and HI assays plotted against the mean result. ${ }^{9}$ Other comparative graphs have a similar aspect. The parallel lines observed correspond to the ascending discrete values of HI logarithmic titres. The percentage of results within the limits of agreement were $94 \%, 96 \%$, and $97 \%$, respectively, for LEIA compared with HI, LA compared with HI, and LEIA compared with LA. Only one difference exceeded $2 \log _{2}$ and only when LEIA and HI and LEIA and LA were compared. The corresponding serum sample was found to contain rubella IgM antibodies in immunocapture assay.

The results of the tests on sera from 10 patients with seroconversion are listed in table 5. Paired sera from 1 to 8 were obtained from cases of rubella infection and the two last pairs were obtained from patients immunised with RA 27/3 live attenuated rubella vaccine.

The seroconversions corresponding to a minimum of a fourfold titre rise were obtained by all three techniques. LEIA titres were lower or within one doubling dilution compared with the results of $\mathrm{HI}$ or LA techniques. In six cases the rise in LEIA titre was more than one $\log _{2}$ lower than that of LA titres.

\section{Discussion}

We assessed the performance of a new latex enzyme immunoassay using rubella antigen sensitised particles as solid phase and compared the assay with latex agglutination assay and haemagglutination inhibition as reference technique. LEIA is a simple immunoassay using a single test dilution. Up to 89 samples could be processed at once with the calibration panel, a positive, and a negative control. Calibration curves had a good adjustment to a straight line, and a minimum $p$ value of 0.001 may be targeted. Only the necessary volume of latex reagent was pipetted and results were available within 20 to 30 minutes. Objective reading was obtained, while for $\mathrm{HI}$ and LA visual reading of end point titration was occasionally equivocal. In these cases the titre corresponding to the last unequivocal reaction was recorded.

Qualitative results showed a few discrepant results corresponding to borderline values. Other authors obtained the same results, especially false positive results in the $\mathrm{HI}$ assay due to the incomplete elimination of nonspecific inhibitors. ${ }^{37}$ Otherwise a zero LEIA value could be assigned to a sample containing a low titre of IgG antibody. Therefore the LA positive, HI, and LEIA negative sample possibly had an IgG titre of $7 \mathrm{IU} / \mathrm{ml}$, corresponding to the LEIA absorbance value. False positive reactions with contaminated sera have also been described.

Moreover, quantitative results of the three techniques were comparable. The regression lines were not different from the identity line except for the intercept corresponding to a positive value of the differences in titres between LEIA and LA. This bias could possibly be explained by a discrete LA value corresponding to a continuous LEIA value included in the interval between the same discrete value and the next one.

Analysis of the differences showed rather large standard deviation values with limits of agreement over one $\log _{2}$, possibly because the standard deviation of each technique in the repeatability assay was already relatively large. If we consider the classic definition of antibody rise as a titre increase corresponding to two doubling dilutions $\left(2 \log _{2}\right)$, all the differences of results in pairs were within these limits except for one sample containing IgM. The presence of $\operatorname{IgM}$ would partially explain the lower results obtained with the IgG LEIA technique. Taylor considered that a distribution of discrete values with a standard deviation of 0.76 $\log _{2}$ would have at least $95 \%$ of the results within a twofold difference from the mean and would have acceptable variation by the traditional rule. The results of this study agree with this. ${ }^{10}$ As expected, because the same solid phase antigen was used, LEIA results seemed to be more closely related to those of LA. The degree of agreement between LEIA and HI or LA and HI was also found to be acceptable. According to results of other studies, it seemed that it could easily be equivalent to the degree of agreement between two different HI techniques. ${ }^{112}$ The inter-assay and intra-assay coefficients of variation of results of LEIA were comparable with those described for ELISA techniques. ${ }^{13}$ They could certainly be improved by automation. As already described for $\mathrm{HI}$ and LA, seroconversions have been detected by LEIA in the parallel testing that is always recommended in serology. Obviously, it 
cannot be recommended by itself for this purpose, but the results obtained have clearly confirmed the possibility of variation in antibody quantitation. Moreover, some lower, discrepant results were obtained with the LEIA technique compared with those of $\mathrm{HI}$ and LA, possibly because, as already cited, these last two techniques showed IgM and other immunoglobulin isotypes. The development of an indirect IgM test using the LEIA protocol would be workable. A variation in the epitopes involved in the different reactions has also been mentioned. ${ }^{13}$

In conclusion, LEIA for quantitation of rubella IgG would be useful for serology. The test is rapid, the results showed satisfactory agreement with those of LA and HI, and it could be used for immunity testing or detecting a rise in IgG antibodies. Automation and parallel testing with other antigens would also be possible. The cost of the reagent for LEIA is about half that of $\mathrm{HI}$ and a fifth of that of LA, essentially because only one dilution is required for the evaluation of the antibody titre instead of the 10 and eight dilutions systematically tested for $\mathrm{HI}$ and LA titration. The latex reagent is stable and easy to use. It offers a practical choice between rapid agglutination with a few specimens and IgG quantitation in batches up to 96 wells with the LEIA technique.

We thank Mrs Margaret Cadoux for help with the manuscript.
We are grateful to Fumouze Laboratories, Clichy, France, for providing the rubella latex kits.

1 Meegan JM, Evans BK, Horstman DM. Comparison of the latex agglutination test with the hemagglutination inhibition test, enzyme-linked immunosorbent assay, and tion test, enzyme-linked immunosorbent assay, and neutralization test for detection of an
virus. J Clin Microbiol 1982;16:644-9.

2 Bricout F, Nicolas JC, Garbarg-Chenon A. Evaluation d'un test au latex (Rubalex) pour la détection des anticorps de
ricout F, Nicolas JC, Garbarg-Chenon A. Evaluation d'un rubéole. Feuillets de Biologie 1985;141:53-6.

3 Väänänen P, Häiva VM, Kokela P, Meurman O. Comparison of a simple latex agglutination test with hemolysis-ingel, hemagglutination inhibition, and radioimmunoassay for detection of rubella virus antibodies. J Clin Microbiol 1985;21:793-5.

4 Felten A, Bondard I, Ciraru N, Barrier J. Interprétation du niveau de l'immunitë rubéolique déterminée par inhibition de l'hémagglutination, agglutination de particules de tion de l'hemagglutination, agglutination de particules de
latex, technique immunoenzymatique. Médecine et Maladies Infectseuses 1986;11:587-91.

5 Simor AE, Chua R, Donald EL. Evaluation of a new latex test and a new enzyme immunoassay for determination of rubella immunity. J Clin Microbiol 1988;26:1582-3

6 Duverlie G, Roussel C, Driencourt M, Orfila J. Microparticle enzyme immunoassay for determination of Immunoglobulin G antibodies to human cytomegalovirus. J Clin Microbiol 1988;26:2229-30.

7 Forsgren M. Standardization of techniques and reagents for the study of rubella antibodies. Rev Infect Dis 1985; 7:S129-32.

8 Bland JM, Altman DG. Statistical methods for assessing agreement between two methods of clinical measurement. agreement between two
Lancet 1986;i:307-10.

9 Johnson J, Duffy K, New L, Holliman RE, Chessum BS. Direct agglutination test and other assays for measuring
antibodies to toxoplasma gondii. J Clin Pathol 1989;42:536-41.

10 Taylor RN. Measurement of variation and significance in serologic tests. Ann NY Acad Sci 1983;420:13-21.

11 Hall EC, Felker MB. Reproducibility in the serological laboratory Health Lab Sci 1970;7:63-8.

12 Castellano GA, Madden DL, Hazzard GT, et al. Evaluation of commercially available Diagnostic test kits for rubella. $J$ Infect Dis 1981;143:578-84.

13 Enders G, Knotek F. Comparison of the performance and reproducibility of the various serological methods and reproducibility of the various serological methods and
diagnostic kits for the detection of rubella antibodies. $J$ Virol Methods 1985;11:1-14. 